\title{
James Nevins Hyde †
}

Mit aufrichtigem Bedauern verzeichnen wir den Tod eines der bekanntesten und vornehmsten Vertreter der amerikanischen Dermatologie: James Nevins Hyde ist am 6. September d. Js., wenige Monate nachdem er sein 70. Lebensjahr erreicht hatte. auf seinem Landsitze in Maine infolge eines Herzschlages plötzlich und schmerzlos verschieden. Von 1879 und bis zu seinem Ende Professor der Dermatologie und venerischen Krankheiten an dem bekannten Rush Medical College in Chicago, zweimal Präsident der amerikanischen Dermatologengesellschaft, Verfasser eines weit verbreiteten Lehrbuches, das seit 1883 acht Auflagen erlebte, war Hyde wohl der $\Gamma$ Ührigste unter den amerikanischenSpezialärzten, von einem Enthusiasmus und einer Arbeitskraft bis zu seinem Ableben, die seiner Jahre spotteten und für seine jüngeren Kollegen ein steter Ansporn waren. Hyde dürfte den meisten europäischen Dermatologen in angenehmer Erinnerung sein. denn selten fehlte er auf internationalen Kongressen, und sein munteres. liebenswürdiges. tolerantes Wesen machte ihm überall rasch Freunde. Auch war er korrespondierendes oder Ehrenmitglied mancher europäischen Spezial$\Lambda$ ereine. Für die Kenntnis der Blastomykose hatte er in den letzten zehn Jahren selbständig und durch Anregung von Arbeiten seiner Assistenten Xamhaftes geleistet. War Hyde auch kein origineller oder bahnbrechender Forscher, so bleibt ihm doch ob seiner allgemeinen Tüchtigkeit in unserem Fache, seiner biederen, charmanten Peisönlichkeit, seiner begeisterten Förderung aller unser Spezialinteressen ein warmes und ehrendes Gedenken bei alien, die ihn kannten, gesichert. Zeisler-Chicago. 